\section{Nominations Being Accepted for MRS Outstanding Young Investigator Award}

Nominations are being accepted for the Materials Research Society's Outstanding Young Investigator Award. This annual award consists of a $\$ 1,000$ cash prize and a citation plaque. Reasonable travel expenses to attend the MRS meeting at which the award is presented and the meeting registration fee will be reimbursed. Each winner will be invited to present a general-interest talk to be featured within the structure of the meeting.

\section{Rules and Eligibility}

A nominee must be a young scientist or engineer who has contributed in an outstanding and innovative way to the progress of materials research; the work should have a significant interdisciplinary aspect. The nominee shall not have reached his/her 36th birthday prior to 1 January of the year in which the award is made. A nominee need not be a member of the Materials Research Society, and nominees of any national origin or citizenship are eligible.

\section{Nomination Procedure}

A package containing the following is required for nomination for the award: 1 . A statement by the nominator supporting the candidate's suitability for the Award with respect to:

- innovative and creative nature of the candidate's work,

- interdisciplinary character of the candidate's work, and

- potential shown by the candidate as a future leader in materials research.

2. Supporting information and documents, e.g., curriculum vitae including birth date and a current publication list. Up to three important papers relevant to the award contribution may also be included.

3. Letters of support from two established scientists familiar with the nominee's qualifications and area of research. Only two such letters will be accepted with each nomination. Each letter should make specific reference to the three criteria in item 1.

4. A list of supporting documents submitted. The entire nomination package, including reprints, should not exceed 10 pages.

Nomination packages for the Outstanding Young Investigator Award to be presented at the 1993 MRS Spring Meeting, should be submitted by November 1, 1992 to: John B. Ballance, Executive Director, Materials Research Society, 9800 McKnight Road, Pittsburgh, PA 15237.
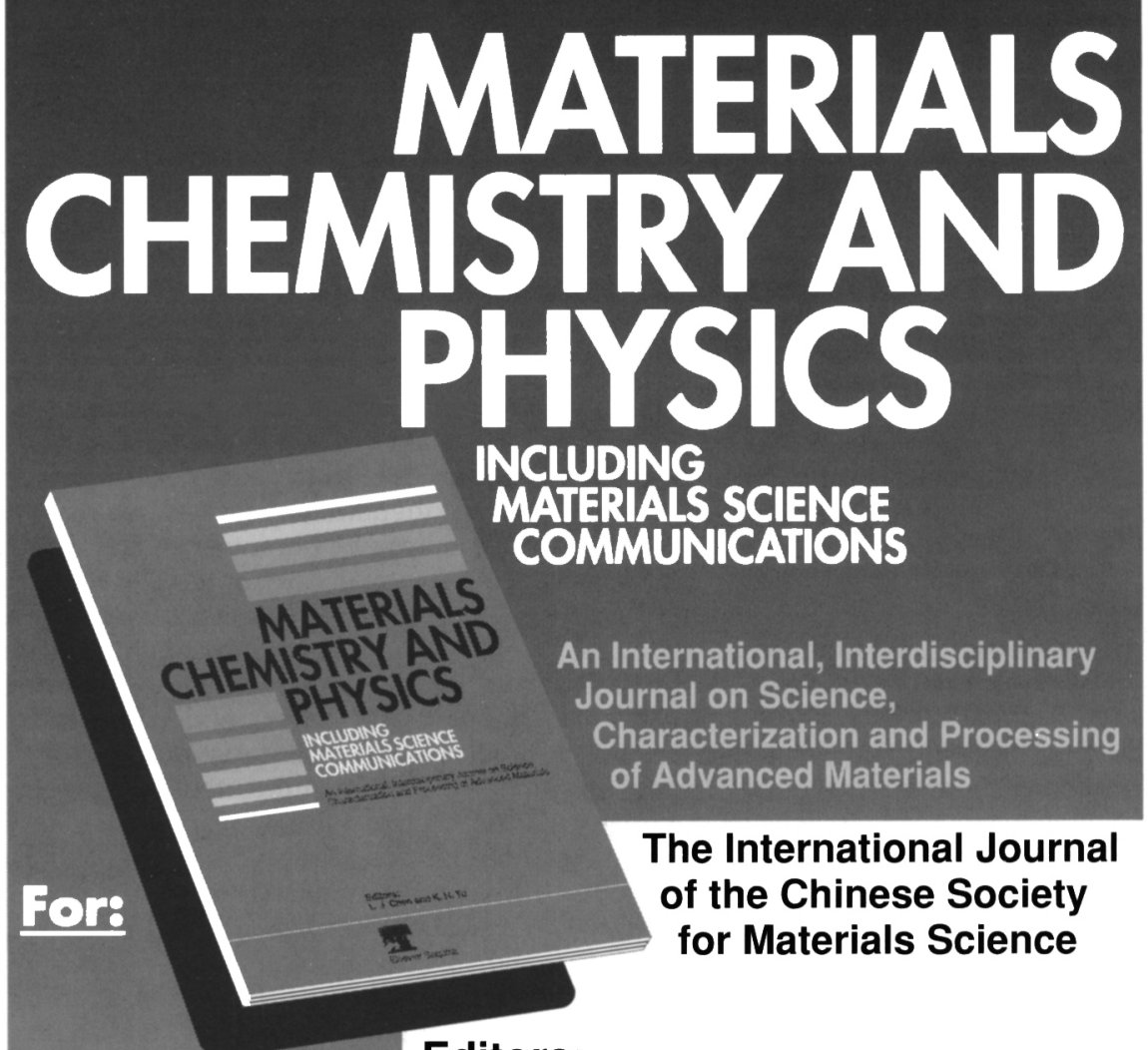

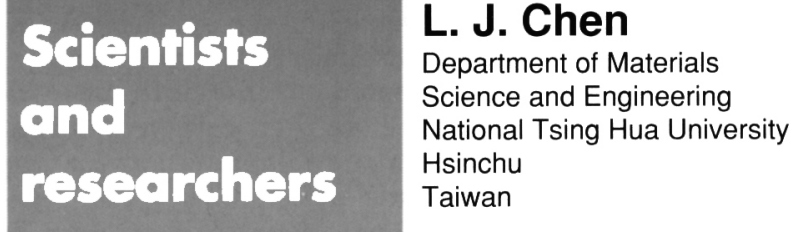

working in
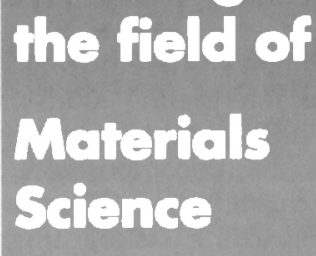

- Ind
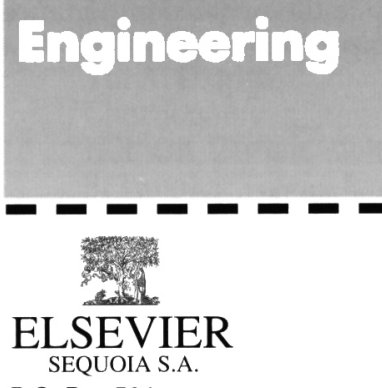

P.O. Box 564

$\mathrm{CH}-1001$ Lausanne 1, Switzerland

Tel.: +41 (21) 207381

Fax: +41(21) 235444 or 232545

For customers in the U.S.A.

and Canada:

Elsevier Science

Publishing Co., Inc.

Attn.: Journal Information Center

655 Avenue of the Americas

New York, NY 10010, U.S.A

Tel.: +1 (212) 633-3750

Fax: +1 (212) 633-3764

\author{
K. N. Tu \\ IBM Research Division \\ T. J. Watson \\ Research Center \\ Yorktown Heights, NY \\ USA
}

Materials Chemistry and Physics is devoted to reports of original research and review articles on interrelationships among structure, properties, processing and performance of materials.

The Editors welcome manuscripts on thin films, surface and interface science, materials degradation and reliability, metallurgy, semiconductors and optoelectronic materials, fine ceramics, magnetics, superconductors, specialty polymers and composite materials.

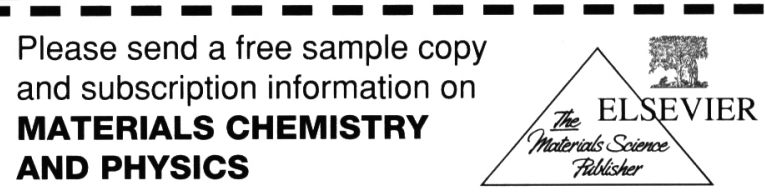

Name:

Company/Institute:

Street:

City:

Country:

Postal Code:

Date: Signature: 